\title{
Comment
}

\section{Upland Cotton Case}

\section{Prepared for the ALI Project on the Case Law of the WTO}

\author{
HYLKE VANDENBUSSCHE
}

Université Catholique de Louvain, KULeuven, CORE, and CEPR

\section{What was the case about?}

In 2002, Brazil complained to the WTO Dispute Settlement mechanism that the US subsidies for upland cotton were depressing the price on the world market for cotton. According to Brazil, this price depression caused serious prejudice to the Brazilian producers of upland cotton. A WTO Panel was installed to investigate this complaint and to prepare an advice to the Appellate Body, the decision organ of the WTO. The Panel came to the conclusion that, indeed, US subsidies were a violation of the 'Agreement on Subsidies and Countervailing Measures (SCM)'. In line with the Panel's analysis, the Appellate Body decided that US subsidies were causing serious prejudice to Brazil and were therefore illegal in a WTO framework.

Sapir and Trachtman rightly point out that the case on upland cotton shows that from a legal and economic point of view the argumentation of the Dispute Settlement Panel was weak. The Panel insufficiently demonstrated a causal link between the US subsidies and serious prejudice required by law.

Sapir and Trachtman convincingly argue that under a correct interpretation of the law under Article 6.3(c) of the SCM agreement, it does not suffice to show that the US subsidies are $a$ cause of serious prejudice (together with other causes), but it requires a demonstration that even taken in isolation, the subsidies cause serious price depression.

Therefore, from an economic point of view, the Panel should have tried to disentangle the effect of a US subsidy on world-market prices for upland cotton from other potential causes of price depression. This would have allowed the Panel to verify whether the US subsidies by themselves were a cause of price depression and how much the subsidies contributed to the price depression.

Sapir and Trachtman argue in favor of the application of more rigorous economic methods in the determination of causality in serious-prejudice cases like the 
Upland Cotton case. Notably, the use of econometric and simulation techniques are considered necessary tools to disentangle different causes of price depression.

The purpose of my discussion below is to support this recommendation by Sapir and Trachtman by means of a graphical exposition that sheds some additional light on how economic analysis can be used for the causation analysis. The discussion will make evident that determining causality is not a simple task, which is why it should best be left to economic experts as will be argued below.

The weakness of the causality investigation in serious-prejudice cases like Upland Cotton is also prevalent in other types of cases. For example, the 'Antidumping Agreement', under Article 6 of the GATT, argues that in dumping cases a causal link is required between the dumped imports and the injury to the domestic industry of the importing country. At present, in most cases, this causality investigation is limited to a trends analysis. Whenever a rise in imports coincides with a fall in domestic-industry performance indicators this is often regarded as sufficient evidence of causality between dumped imports and injury to the domestic industry. Instead of this casual empiricism, the framework outlined below could also be used to determine causality in dumping cases as shown in Vandenbussche (1996).

\section{Several causes for price depression are possible}

The purpose of any quantitative analysis aimed at measuring the effects of US subsidies on world-market prices requires the construction of a counterfactual world. This counterfactual world gives an idea of what the price would have been in the absence of subsidies.

In the absence of any knowledge on the market structure for upland cotton, the simple assumption of a competitive market can be a starting point. This would suggest that prices are determined by the interaction between world supply and world demand, as illustrated in Figure 1. This in not an innocuous assumption but one that would need to be verified empirically before modeling the market structure, as explained more in Section 3.

Upland cotton, in view of its nature, is likely to be a homogeneous type of product, i.e. where it is hard for any customer to distinguish between different types of upland cotton. But again this is an assumption that would need to be verified empirically since product differentiation is likely to alter the analysis. For expositional purposes, we will assume that US and Brazilian upland cotton are perfect substitutes, i.e. consumers do not make a distinction between them.

In terms of supply, the case details suggest that the US is the largest exporter of upland cotton and that Brazil also is a major export competitor. From this it follows that both countries seem to account for a large share, if not most of, the world supply of upland cotton.

In order to construct a counterfactual world, it is necessary to have an adequate reference period that is a period where there was no price depression. In the 
Figure 1. Price depression in the world market for upland cotton

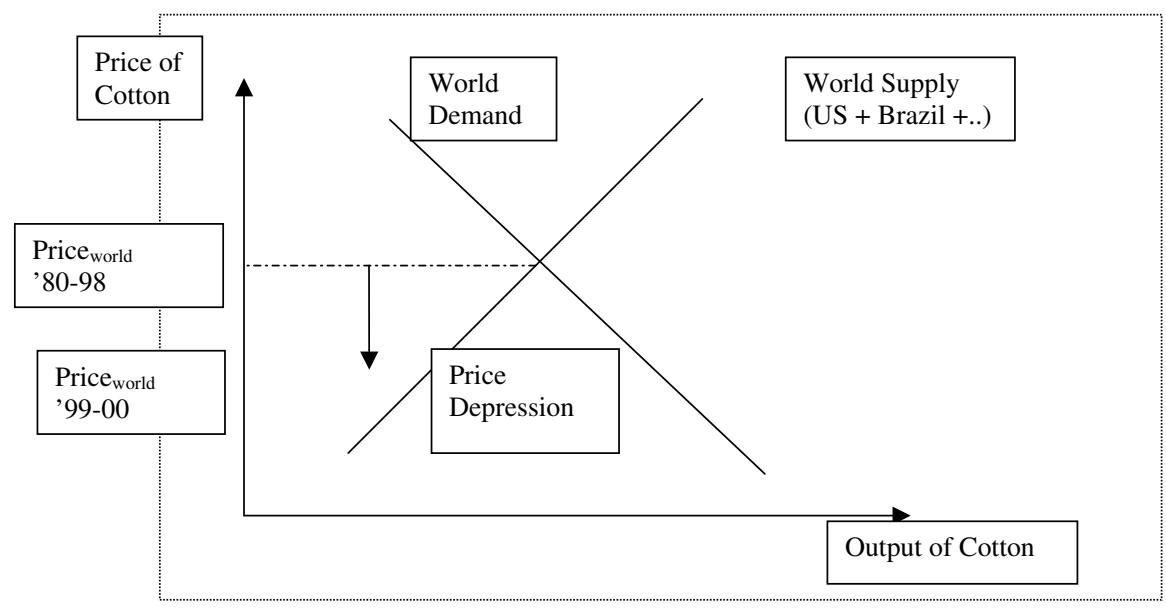

Upland Cotton case, the reference period used was the average world-market price for upland cotton over the period 1980-1998. This price was considered to reflect the price without US subsidization. Figure 1 shows how this reference price is given by the intersection of world demand and supply of upland cotton. The correct position and slope of the demand and supply curve is given by the elasticities of demand and the elasticity of supply respectively. These elasticities will prove crucial for the remainder of the exposition and are part of the essential information that the WTO Panel should have when analyzing the effects of US subsidies on prices.

Elasticities can be obtained through econometric techniques as long as one has a sufficiently long time span or a sufficiently high frequency of transactions data in a market. ${ }^{1}$ Once the elasticities are known, the correct position and slope of the demand and supply can be inferred and a counterfactual world like the one in Figure 1 can be modeled using a structural equations model.

If a drop in the world-market price for upland cotton below the reference price is observed, as was the case in the period 1999-2000, either a shift in the supply curve of upland cotton or a shift in the demand curve or both will be the underlying cause.

A subsidy to a US farmer will imply that each US farmer will now supply more upland cotton to the export market for any given price. Or, in other words, the

1 See, for example, Angrist and Krueger (2001) for more details. The estimation of elasticities requires the use of instruments, i.e., demand and cost shifters that allow the identification of separate supply and demand curves respectively from using price and quantity data. A typical example of a demand shifter is the price of a substitute product. A typical example of a cost shifter of agricultural products is yield per acre. A demand shifter is used to identify the supply function and a cost shifter is used to identify the demand curve. 
Figure 2. Cause 1: subsidy shifted the world-supply curve outward

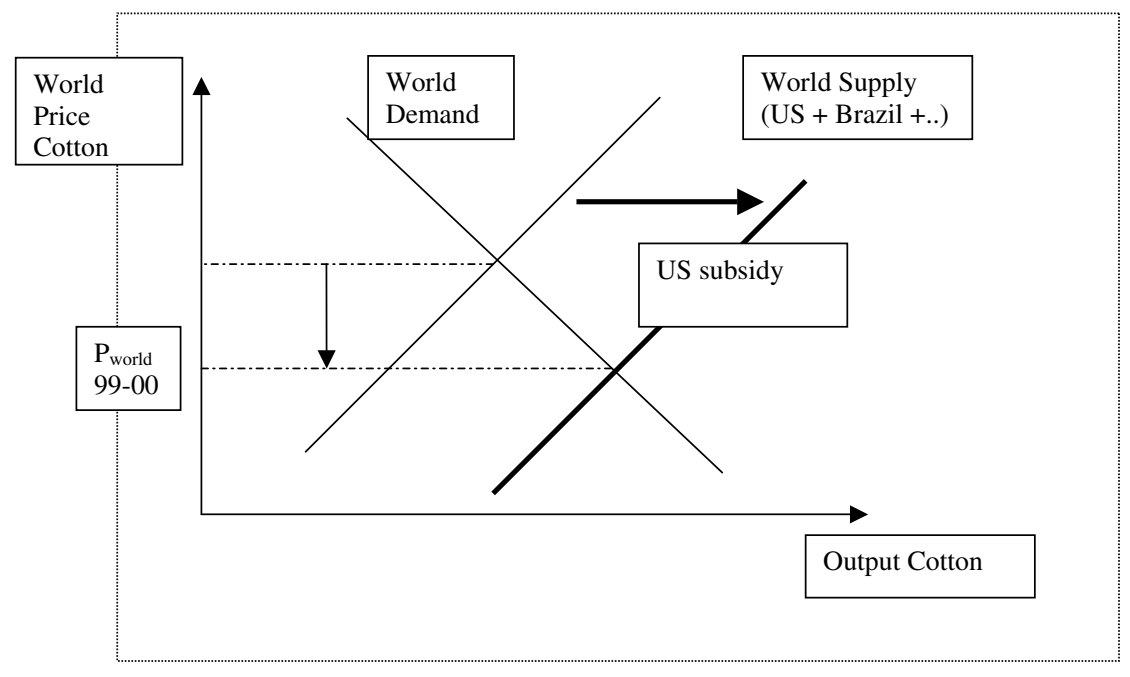

world-supply curve in Figure 2 is going to shift to the right. The extent of this shift will depend on the amount of the subsidy. ${ }^{2}$ In Figure 2, we show a situation where the US subsidy is accountable for the total price depression in the world market observed in the market.

However, it is clear that demand factors could also have accounted for the fall in the world-market price in the period 1999-2000. This is illustrated in Figure 3. In fact, the price movements of substitute products like synthetic fibers, during that same period, may have resulted in an inward shift of the demand for upland cotton. In other words, rival products on the market may have reduced the demand for upland cotton. In Figure 3, we show a scenario in which the inward shift in demand completely accounts for the fall in the price of upland cotton observed on world markets.

The size of the demand shift will depend on the cross-price elasticity of synthetic fibers and upland cotton. The cross-price elasticity captures the extent to which the demand for upland cotton is affected by the price of substitute products such as synthetic fibers. Or, in other words, it captures the degree of substitutability between the two types of products and is another parameter that would need to be estimated econometrically after which its value could be inserted in a structural model such as the one presented in Figure 3.

A third possibility is that the world-market price for upland cotton has fallen due to a combination of demand and supply shifts.

2 For expositional purposes, we abstract from other variables that could affect the shift of the supply curve like the exchange rate of the dollar. 
Figure 3. Cause 2: substitute products for cotton can shift the world demand for cotton inward

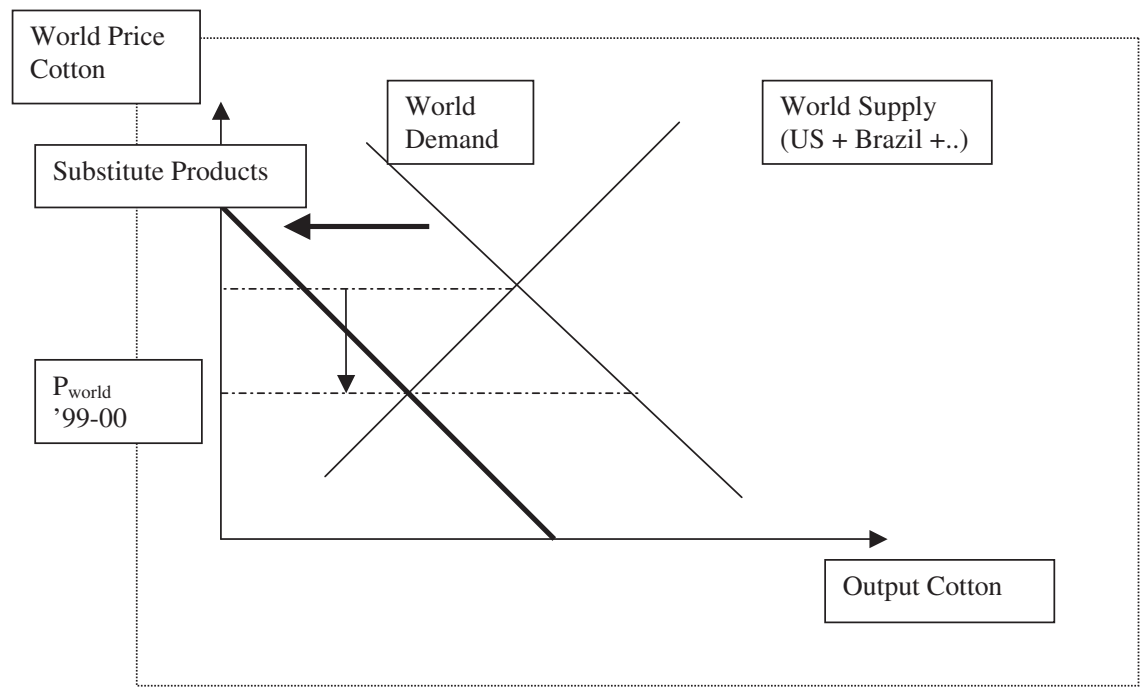

While Figures 2 and 3 above clearly indicate that several reasons could underlie the drop in the price for upland cotton, no attempt was made by the WTO Panel to disentangle the effects at work. Implicitly, a scenario such as the one in Figure 2 seemed to be what the Panel had in mind, i.e. that the US subsidy accounted for most, if not all, of the price depression.

A simulation model operating along the lines of the one presented above was put forward by Brazil. That model claimed to have disentangled the effect of the US subsidy on the world-market prices and argued that world price would have been $12.6 \%$ higher in the absence of a US subsidy.

The US criticized the model saying that the elasticity of demand was assumed to be too inelastic, i.e. too steep a slope of the demand curve was assumed, thereby attributing too big a role to the effect of the US subsidy on the price decrease. Indeed, it can be seen from Figure 3 that if a steeper demand curve is assumed, an outward shift in the supply curve will result in a larger drop of the equilibrium price on the world market.

At the other extreme, in the case of a flat demand curve (with a demand elasticity of infinity), an outward shift of the supply curve would not affect the price at all, in which case the US subsidies would not be the underlying cause of the serious prejudice. With a flat demand curve, the only cause of a price reduction would be a downward shift in the demand curve.

The Panel's reply points out that without its own reliable estimates of the relevant elasticities, it is not in any position to counter arguments like the one raised 
by the US. The Panel replied that, in reaching its decision, it had not relied on the quantitative analysis prepared by the Brazilian party.

Whether or not the Brazilian estimates were the right ones is not the issue here. The heart of the problem is that the Panel did not have its own independent estimates, and may have found it hard to rest its case solely on evidence provided by one of the parties involved in the dispute. This lack of information makes the Panel's analysis look arbitrary and makes its decision process vulnerable to critique.

\section{Causality determination is work for economic experts}

Even from the sketchy outline above, it should already be clear that the estimation of a structural model with demand and supply parameters involving, amongst others, elasticities and cross-price elasticities is not an easy thing to do.

Moreover, for expositional purposes, we have made a number of simplifying assumptions that need not hold. The model used above assumes that the market for upland cotton is relatively competitive and that the price on the market is the outcome of joint demand and supply forces. Or, in other words, it assumes that farmers in the market are atomistically small such that their individual output has no effect on world markets. However, in reality, market conditions could be very different. In order to find out to what extent this assumption is true or violated, a thorough analysis of the market structure is required. Does the industry consist of many small farmers or are there large agricultural firms involved? This matters a lot in terms of industry structure and intensity of competition.

A related issue is the assumption on product differentiation. For simplicity, we have assumed that US cotton and Brazilian cotton are like products with little differentiation between them. However, this may not be a realistic assumption. In fact, in most markets, products are differentiated. Standard models from the literature in industrial economics point out that product-market competition is less fierce in more differentiated industries than in homogeneous products. Therefore, a US subsidy is likely to have larger price effects when upland cotton is a very homogeneous product than when the industry is characterized by differentiation.

The simple conclusion is that the causality investigation between subsidized exports and serious prejudice deserves a more in-depth economic analysis.

Sapir and Trachtman see a possibility for this within the context of the existing legislation, notably the use of Article 13.2, which foresees the possibility to install 'economic expert review groups'. The purpose of these experts would be to use various alternative methods, in the spirit of the one presented above, to address the causality issue on the basis of which the Panel could base its decision. With its own estimates of the relevant parameters involved, the Panel would be equally, if not better, informed than the parties involved. This would allow the Panel to include the quantitative estimates in its decisionmaking, which would largely improve the economic foundations on which it would rest its case. 
I sincerely hope that the WTO takes this advice to heart and pursues the possibility of installing economic experts in future dispute cases. The 'outsourcing' of the causality investigation to economic experts will facilitate the decisionmaking by WTO Panels, and put them in a better position to defend their decisions vis-àvis complainants and defendants involved in a case. It will also help them to better pursue the legal objectives of the WTO rules. Given that causality is also an essential element in the decisions surrounding antidumping cases and safeguard cases, WTO decisionmaking in those areas could also be improved. This, in turn, will result in the enhanced credibility and reputation of the WTO, which seems essential for its proper functioning in a more globalized world.

\section{References}

Angrist, J. D. and A. B. Krueger (2001), 'Instrumental Variables and the Search for Identification: From Supply and Demand to Natural Experiments', Journal of Economic Perspectives, 15(4): 69-85.

Boltuck, R. (1991), 'Assessing the Effects on the Domestic Industry of Price Dumping', in P. K. M. Tharakan (ed.), Policy Implications of Antidumping Measures, North-Holland, pp. 99-141.

Vandenbussche, H. (1996), 'Is European Antidumping Protection against Central Europe too High?', Weltwirtschaftliches Archiv/Review of World Economics, 132: 116-138. 